\title{
Land Cover Change Detection Using MSS and MODIS Data: A Case Study for Liangshan-Xiangling Region in Southwestern China
}

\author{
X. Y. Song and J. B. Li \\ Environmental Science and Engineering Program, University of Northern British Columbia, Prince George, BC V2N 4Z9, Canada
}

Received 20 Decmber 2008; revised 25 Feburary 2009; accepted 2 March 2009; published online 10 June 2009

\begin{abstract}
As a result of rapid socioeconomic development and climate change, the land cover has been changing in the mountainous areas in southwestern China while the associated ecological environment has been seriously disturbed. This study is to quantify the land cover change in Liangshan-Xiangling Region in Sichuan Province in China from the 1970s to present and to compare the land cover change rates among different land cover types. Two groups of remote sensing data, including MSS data in 1974-1980 and MODIS data in 2002-2007, were utilized to investigate the land cover changes during different time periods in the study area. The NDVI differencing and unsupervised classification compassion methods were used to detect the land cover quality and quantity changes. The results showed that the vegetation cover in the study area decreased significantly in the 1970s, but increased in recent years due to the establishment of nature reserves and enhancement of environment protection.
\end{abstract}

Keywords: change detection, remote sensing, land cover, NDVI, unsupervised classification

\section{Introduction}

Land cover change detection is the process of identifying differences in land cover at different time periods, and it could provide relevant decision makers with sound information for developing effective strategy to improve the natural environment (DeFries et al., 1997). Before the 1970s, most of the studies on change detection were based on manual collection of data which was associated with low efficiency, long period and huge amount of work. The manually collected data in each study is usually hard to be used for other further studies, and it is thus extremely difficult to use this method to detect land cover changes in large-scale problems (Liu, 2001). Recently, the earth-orbiting satellites have provided much convenient means for obtaining digital remote-sensed data in many application areas. Due to the advantages of quick processing and accuracy, remote sensing has become a very easy means to evaluate the extent of land cover change and the associated impacts on aquatic and terrestrial environments (Jones et al., 2001; Mas, 1999; Stefanov and Netzband, 2005).

As compared with other remote sensing, Landsat Multispectral Scanner (MSS) sensor provides the longest and continuous remotely sensed satellite historic record. The MSS data could span a time period from 1972 to present (Nelson et al., 2002). Several research studies have been conducted using

\footnotetext{
${ }^{*}$ Corresponding author. Tel.: +1 250 9606397; fax: +1 2509605845 .

E-mail address: li@unbc.ca (J. B. Li).
}

ISSN: 1726-2135 print/1684-8799 online

(C) 2009 ISEIS All rights reserved. doi:10.3808/jei.200900147
MSS data for land cover change detection. For example, Jensen (1981) developed a suite of image processing techniques for change detection, including image differencing, changevector analysis and comparison of derived classes for multiple dates. They later applied the image differencing technique to use MSS data for identifying urban expansion with an accuracy of $81 \%$ (Jensen and Toll, 1982). Munyati (2000) used hightemporal-resolution MSS imagery to monitor changes in wetland vegetation. Nelson et al. (2002) used MSS data to quantify the land cover change in a wetland in Louisiana and examined the land cover change rates among various land cover types within a long time span $(1972 \sim 1992)$. In recent years, several new satellite sensors have been launched for geological exploration, and another new generation of advanced optical sensor, Moderate Resolution Imaging Spectroradiometer (MODIS), has been widely used in change detection. The MODIS is onboard the Terra and Aqua satellite platform and is capable of providing additional shortwave infrared bands that are sensitive to vegetation index. In comparison with NOVA/AVHRR, the higher resolution (i.e. $250 \mathrm{~m}$ ) and narrower spectral bandwidths of MODIS had made it more useful in vegetation and land cover studies (Malingreau, 1989). The MODIS sensor has 36 spectral bands, seven of which are designed for the study of vegetation and land surfaces, including blue ( $459 \sim 479 \mathrm{~nm})$, green $(545 \sim 565 \mathrm{~nm})$, red $(620 \sim 670 \mathrm{~nm})$, near infrared (NIR1: $841 \sim 875 \mathrm{~nm}$; NIR2: $1230 \sim 1250 \mathrm{~nm}$ ), and shortwave infrared (SWIR1: $1628 \sim 1652 \mathrm{~nm}$, SWIR2: $2105 \sim 2155 \mathrm{~nm}$ ). MODIS provides an improved source of global information for the study of land surfaces with varying spatial resolutions of $250 \mathrm{~m}$ to $1 \mathrm{~km}$ depending on the bandwidth. The data from two MODIS bands (red and near infrared) are usually used to investigate 


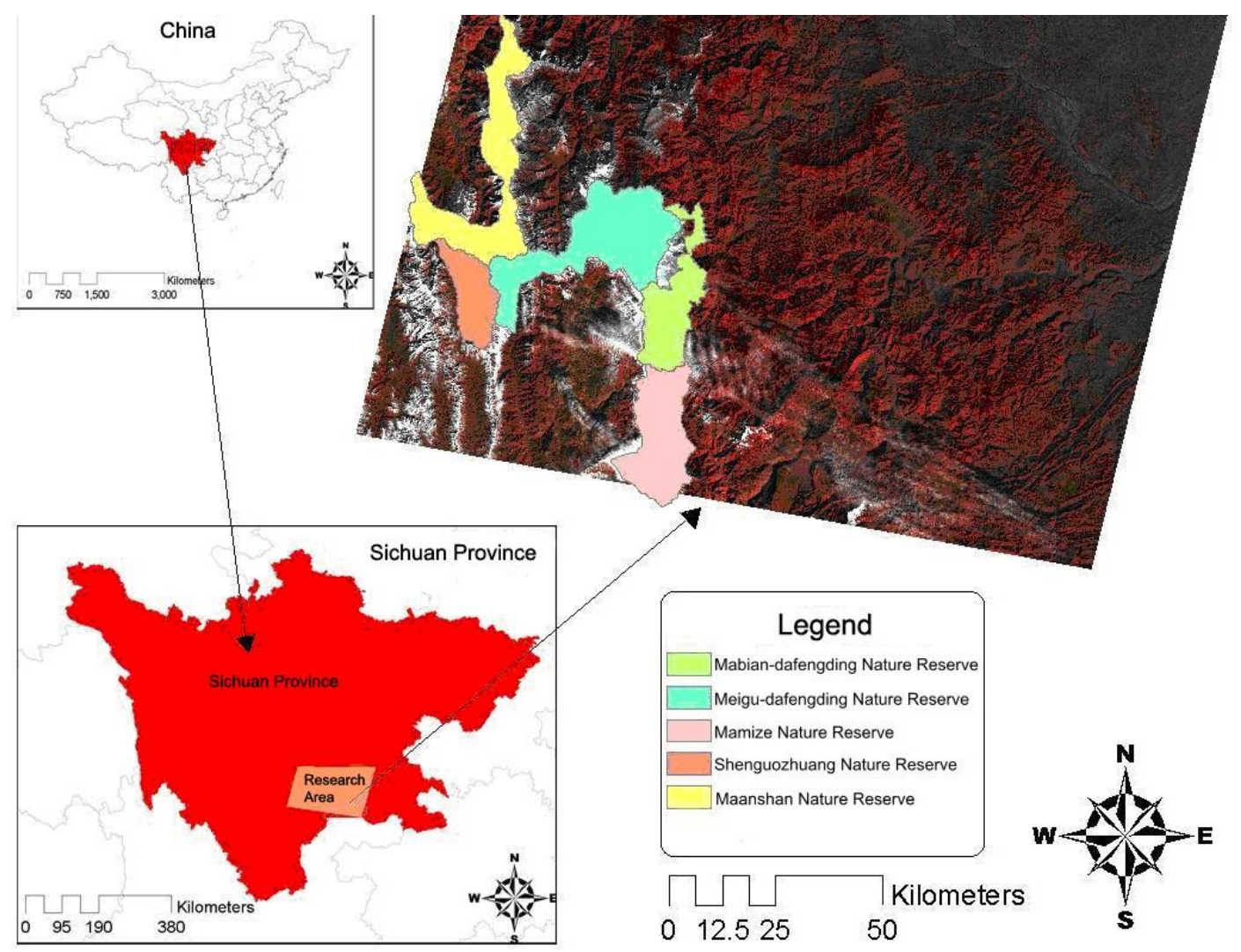

Figure 1. Overview of the study area.

many land cover changes caused by human activities which occur at spatial scales near $250 \mathrm{~m}$ (Townshend and Justice, 1988).

Under the influences of rapid socioeconomic development and climate change, the land cover in the mountainous areas in southwestern China has been greatly changing, and the ecological environment has also been seriously disturbed. Such changes would not only affect the structure of the fragile ecological environment, but also adversely decrease the area of habitats for endangered species and bring serious negative impacts to the distribution and survival of endangered flora and fauna species. In order to make informed decisions of ecological and environmental protection, it is of great importance to quantify the land cover changes within such areas. In this study, a case study in Liangshan-Xiangling region in southwestern China will be conducted to examine the land cover changes from the 1970 s to present using the remote sensing data from MSS and MODIS. The results would provide sound basis for the region to implement effective strategies for ecological environmental protection and socioeconomic development.

\section{Study Area and Research Data}

Located in the southern part of Sichuan province of China, Liangshan-Xiangling region is in the upper reaches of the Yangtze River and the middle section of the Hengduan Mountains $\left(102^{\circ} 2^{\prime} \mathrm{E} \sim 104^{\circ} 9^{\prime} \mathrm{E}, 28^{\circ} 3^{\prime} \mathrm{N} \sim 29^{\circ} 2^{\prime} \mathrm{N}\right.$ ) (Figure 1). The re- gion spans hundreds of kilometers from its north to south with most parts having elevations of above 3000 meters. There are five nature reserves in this area with most of which being established after 2000, including Maanshan nature reserve, Shenguozhuang nature reserve, Meigu Dafengding national nature reserve, Mabian Dafengding national nature reserve and Mamize nature reserve. The study area is associated with excellent natural conditions where vast types of rare plants are found, including many original ancient relict plants (i.e. the dawn red-wood, spruce, and Davidia involucrate). A wide range of animals are also found in this region, such as the first-grade state-protected animals of giant panda, takin, south-China tiger, and white lip deer, as well as the secondgrade state-protected animals of red panda (Liu, 2005, 2006; MDNNRA, 2000). The land cover in the study region has been significantly changing during the past years. Thus the understanding and examination of such changes are extremely important for the effective protection of these rare species of plants and animals and their living environments, and also for the long-term benefits of our future generations.

The land cover changes in the study area are evaluated by analyzing the remote sensing data. The MSS data in November 1975 and April 1980 were provided by Chinese Academy of Surveying and Mapping. The MODIS data in April 2002 and April 2007 were the 16-day composite data (i.e. MOD13Q1) and were downloaded from NASA website (LP DAAC, 2007). 


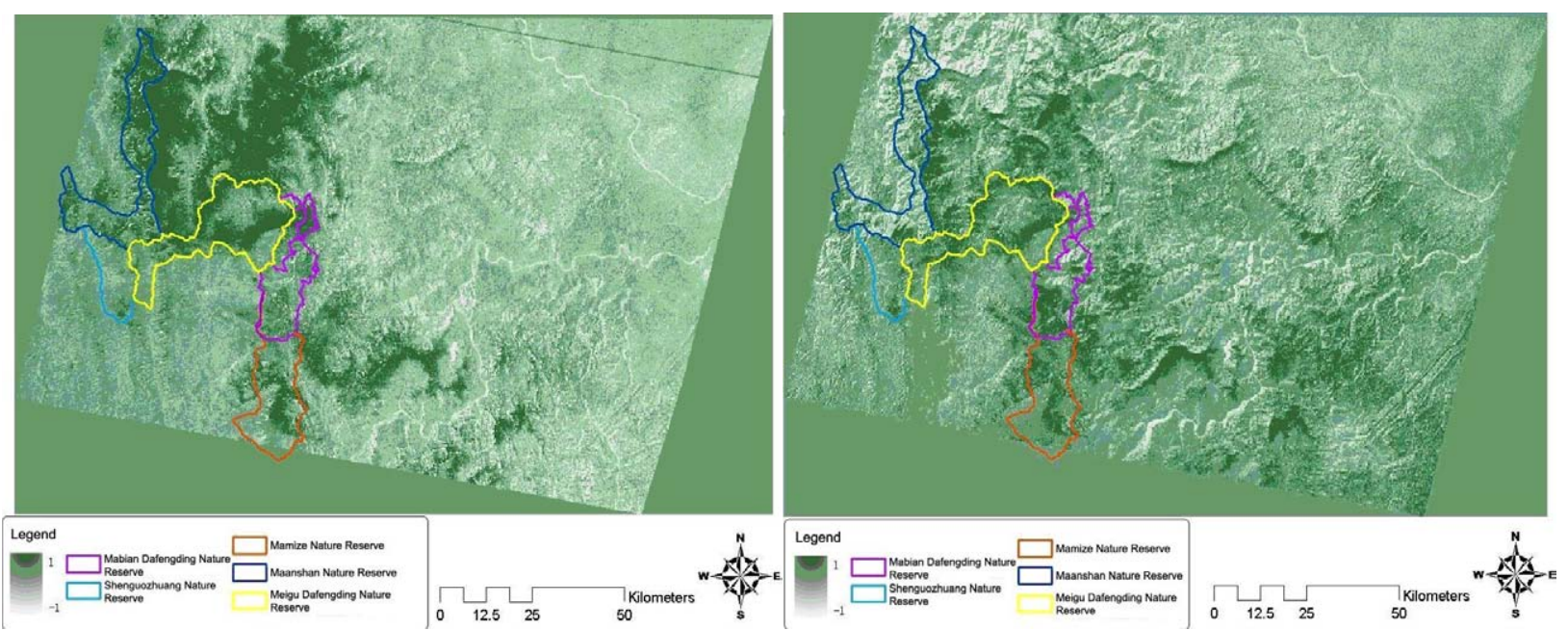

Figure 2. NDVI images using MSS data in Liangshan-Xiangling region (left: 1974, right: 1980).

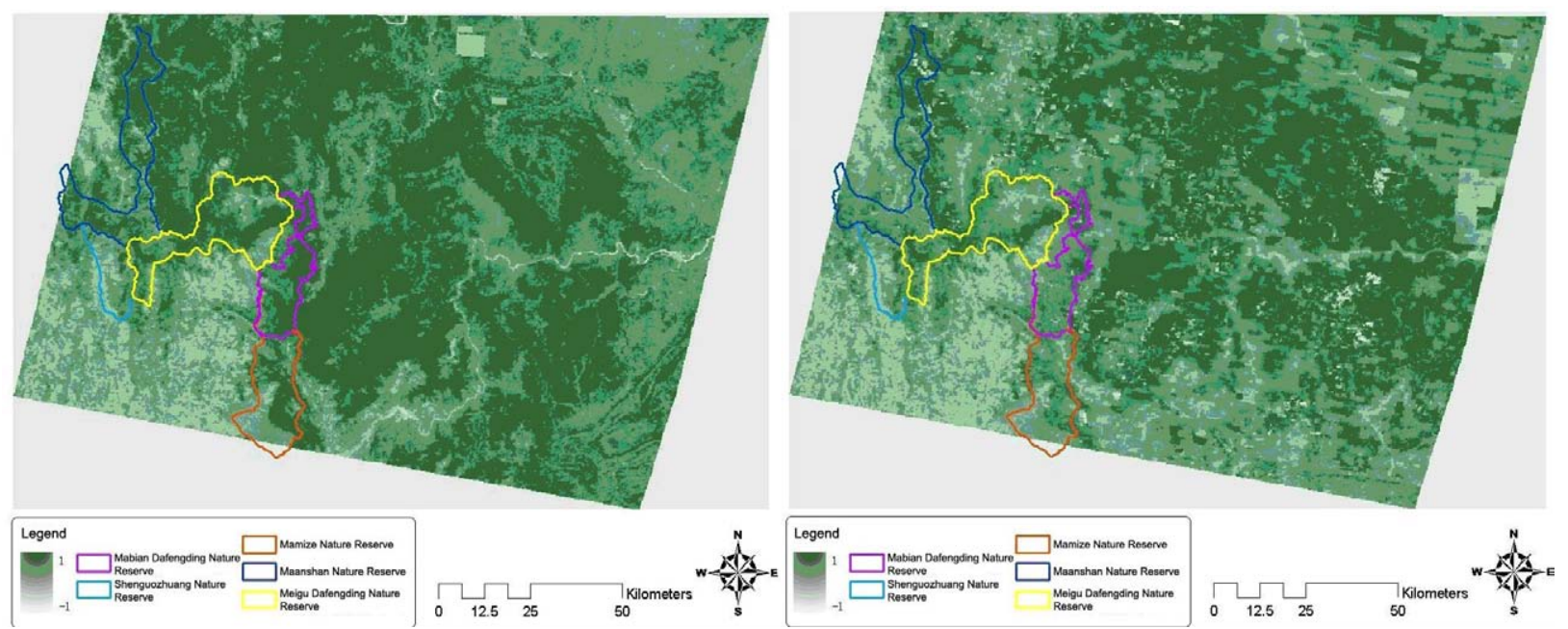

Figure 3. NDVI images using MODIS data in Liangshan-Xiangling region (left: 2002, right: 2007).

According to the characteristics of soil types and vegetation cover conditions of the study area, ten land cover types were included (Jin, 2005; MDNNRA,2000), namely (a) conifer forest $(\mathrm{CF}),(\mathrm{b})$ mixed deciduous broadleaf forest and conifer forest (DCF), (c) mixed evergreen broadleaf forest and deciduous broadleaf forest (EDF), (d) evergreen broadleaf forest (EBF), (e) secondary forest (SF), (f) bamboo (BAM), (g) shrubgrass land (SGF), (h) alpine meadow and scree (AMS), (i) water area (WA), and (j) bare-rock land (BRL). By considering the resolution and differencing ability of the MSS and MODIS data used in this study, the land cover types were further divided into three categories, including (a) bare-rock land (BRL), (b) S-A land (SGF, AMS, WA), and (c) forest (CF, DCF, EDF, EBF, SF, BAM).

\section{Land Cover Change Detection Methods}

The basic idea of using remote sensing data for change detection is that the land cover change could result in variation of the radiance values, and the image data of a given area at different time interval could then be compared to identify the changed pixels (Knight et al., 2006). A variety of methods for land cover change detection have been used during the past years, such as the comparison of land cover classifications, image differencing/rationing, vegetation index differencing, principle components analysis, and change vector analysis. Due to the medium scale and high resolution of the digital satellite data obtained for the study area, two change detection methods were used and compared in this study, including the normalized difference vegetation index and unsupervised classification approaches.

The status of vegetation growth can be described by vegetation index (VI). VI can effectively measure the activity of land surface vegetation and enhance the interpretation of remote sensing images. It has been used for land cover change detection, vegetation coverage density assessment and other ap- 


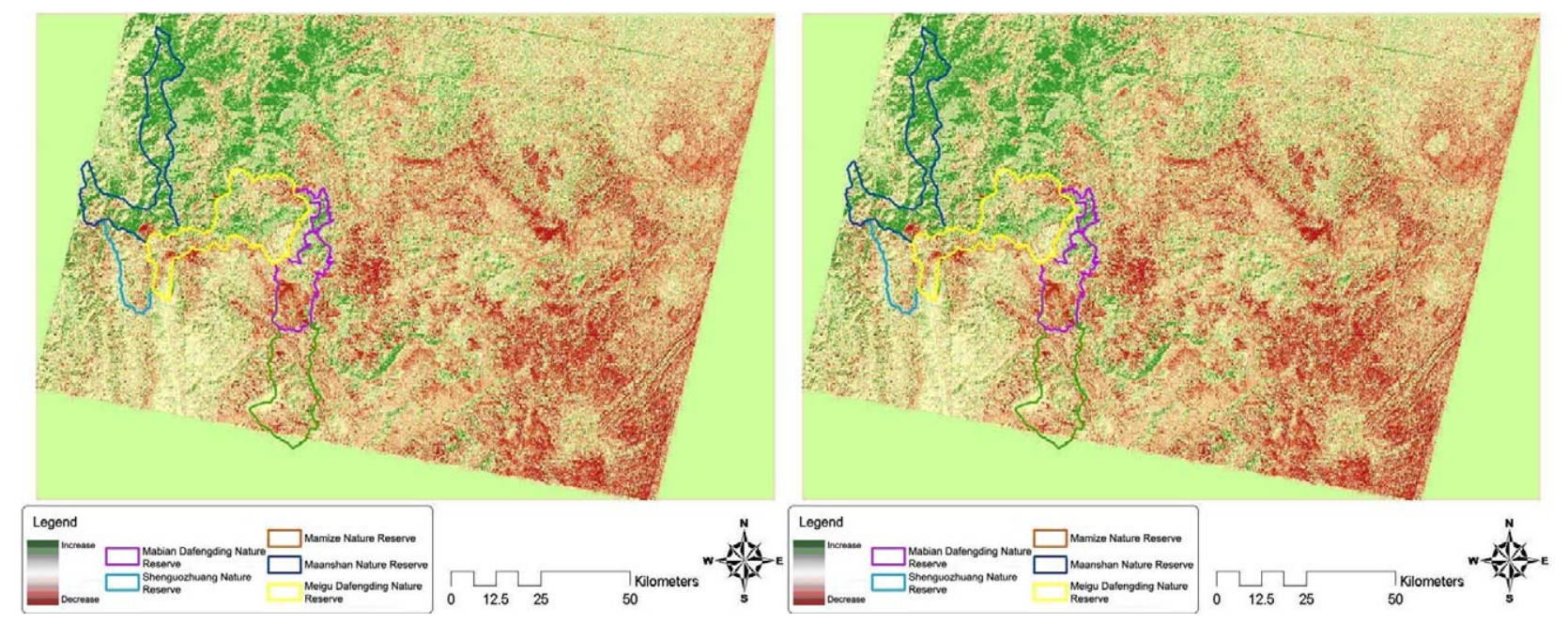

Figure 4. NDVI differencing using MSS data (left: 1974-1980, right: 2002-2007).

plications (Singh, 1989). Many studies have shown that the reflection energy of the red and near-infrared bands was closely related to the amount of surface vegetation cover. For example, the chlorophyll of plants absorbs light energy, and this would result in the decreased reflection energy of red band with plant growth. On the other hand, the healthy plants hardly absorb near-infrared radiation, leading to the increased reflection energy of this band with the plant growth. As a result, based on the characteristics of typical spectral reflection of plant leaves, the empirical vegetation index was introduced. Since the energy absorptions in the blue band $(470 \mathrm{~nm})$ and red band $(670$ $\mathrm{nm})$ are most sensitive, the reflection energy of visible light is extremely low due to the reflection of near-infrared radiation. The difference between red and near-infrared radiation is sensitive to the amount of vegetation, while the areas with no or little vegetation have smaller difference and areas with highly covered vegetation have bigger difference.

Vegetation index can be divided into three categories. The first category includes the indices which are defined by the linear combinations or ratios of the radiations of original bands without considering the impacts of other factors such as the atmosphere, the soil lightness and color. This category of indices include ratio vegetation index (RVI) which was specifically designed for Landsat MSS, and have not been widely applied. The second category is based on more physical knowledge and considers electromagnetic radiation, atmosphere, vegetation cover, soil background and interactions among these factors. Such category of indices include perpendicular vegetation index (PVI), soil adjustment vegetation index (SAVI), angel vegetation index (AVI), and normalized difference vegetation index (NDVI). The third category is developed for hyperspectral remote sensing and thermal infrared remote sensing. In this study, NDVI was used for change detection, and it is defined as follows (Justice et al., 1998):

$N D V I=\left(X_{\text {nir }}-X_{\text {red }}\right) /\left(X_{\text {nir }}+X_{\text {red }}\right)$

where $X$ represents the reflection of radiation received by the satellite, and the subscript "nir" represents near-infrared band, while "red" represents red band.

The unsupervised classification approach is also used for change detection (Singh, 1989). This method only uses statistical measures to classify different remote sensing data, and does not need prior knowledge about the research area. The most commonly used algorithms for unsupervised classification include ISODATA and T-mean, and the ISODATA was chosen for classification in this study.

\section{Results and Discussions}

The change rate of land cover type is used to examine the changes of ecological environment from the 1970s to present in this study. The MSS remote sensing data from 1975 to 1980 were used to analyze the change rate in 1970s, and the MODIS data from 2002 to 2007 were examined to characterize the change rate in recent years.

\subsection{NDVI Differencing}

The NDVI images of land cover types in the study area in 1974 and 1980 are shown in Figures 2 and 3, respectively. According to Equation (1), the areas with darker color represent land cover types that have larger difference between absorption of red-band radiation and near-infrared band radiation. Thus these areas are associated with higher NDVI values and should be the forests regions. On the contrary, the areas with lighter color represent land cover types with smaller difference between the absorption of red-band and near-infrared band radiations, and these areas have much lower NDVI values and represent the bare rock land. The areas with color between the above two groups should be the S-A land.

Figure 4 presents the results of NDVI differencing using MSS data. It can be obviously found that the land cover in the study area greatly changed in the 1970s. The main changes are the vegetation increase in the northwest and decrease in the middle and southeast. The vegetation increase in the north- 


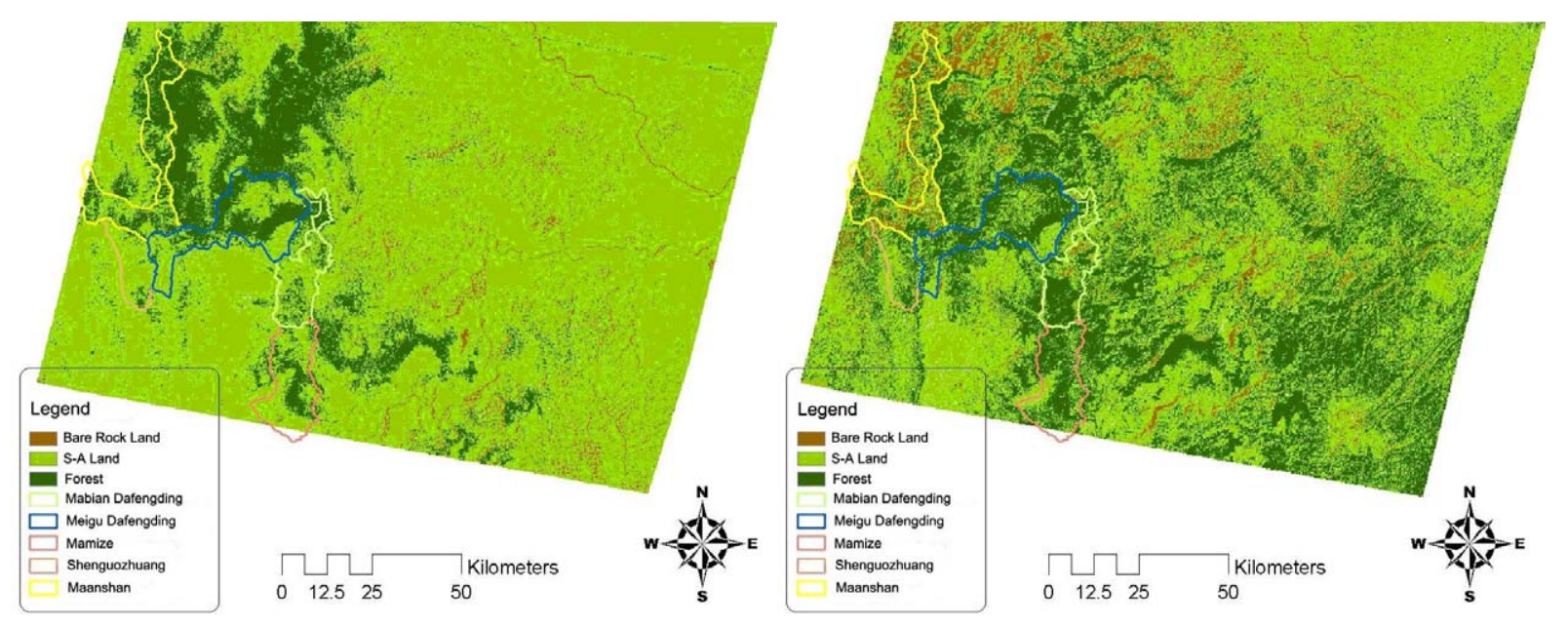

Figure 5. Unsupervised classification using MSS data (left: 1974, right: 1980).
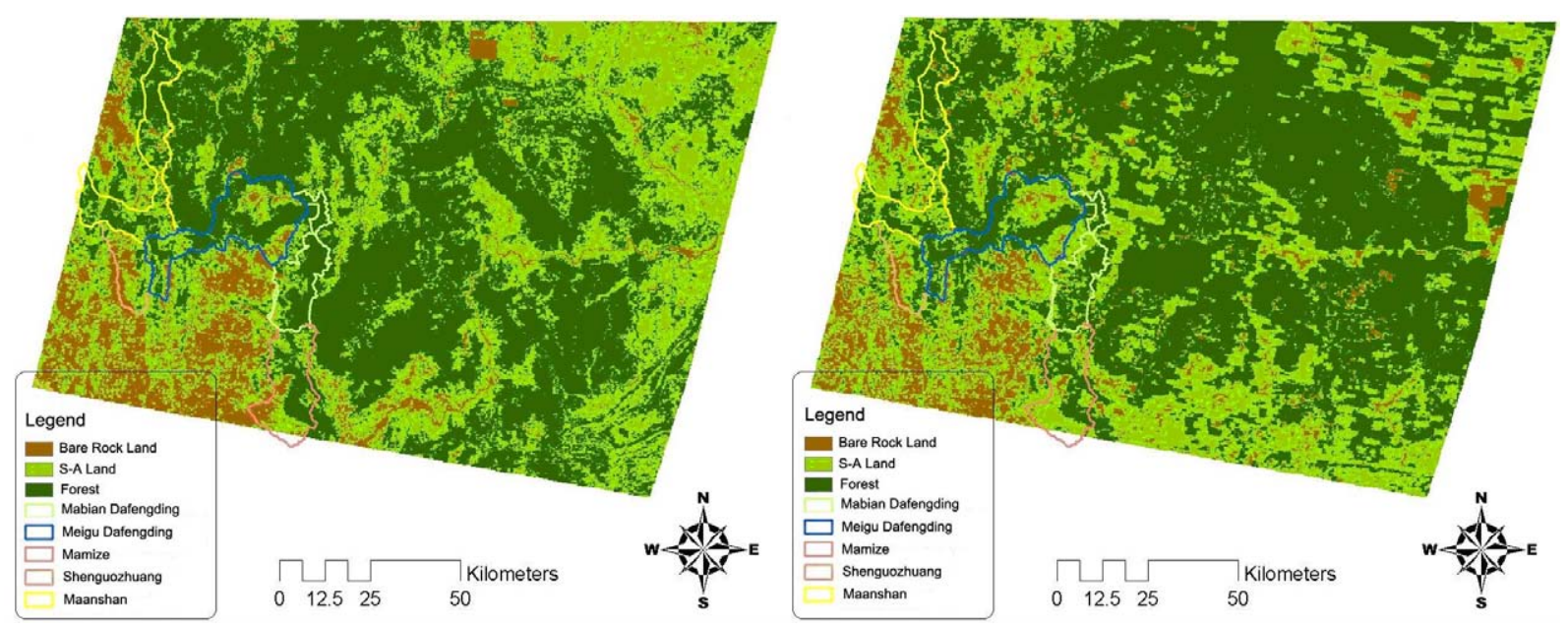

Figure 6. Unsupervised classification using MODIS data (left: 2002, right: 1980).

west is due to the transition from S-A land to forest and from bare rock land to forest, while the vegetation decrease in the middle of the study area is due to the transition from forest to bare rock land and S-A land. The vegetation decrease in the to southeast is due to the transition from huge amount of forest bare rock land and S-A land, as well as from S-A land to bare rock land. In summary, the land cover changing trend in the 1970 s is not optimistic.

By examining the NDVI differencing result in 2002-2007 (Figure 4), it is observed that the NDVI in the study area greatly changed in recent years as well. The vegetation increase is consist of three parts, including transition from S-A land to forest in the northwest, transition from part of the bare rock land and S-A land to forest in the middle, and transition form bare rock land to forest in the southeast. Vegetation decrease mostly occurred in the northeast of the study area. One reason of such decrease is due to the transition from forest to S-A land and bare rock land, as well as from S-A land to bare rock land. In summary, the land cover and environment in the study area have been improving in recent years.
By comparing the NDVI differencing results shown in Figure 4 , it is found that the ecological environment changing trends within different periods are different. The land cover and ecological environment in the study area have been progressing in a positive way in recent years with greatly increased vegetation. On the contrary, the ecological situation in the 1970s was not satisfactory. However, in the northwest of the study area, the vegetation cover was kept in a steady state. This area consists of five nature reserves. Since the establishment in 1978, Meigu Dafengding nature reserve was well protected and the vegetation in this area was kept increasing; Mabian Dafengding nature reserve and Mamize nature reserve were established after 2000, and the implementation of environmental protection and reforestation policy have significantly changed the ruined land in these areas which were destroyed by excessive deforestation in the late 1970s and early 1980s, resulting in obviously increased vegetation in these areas in recent years; the status of land cover in Maanshan nature reserve has been stable; although the vegetation in Shenguozhuang nature reserve was decreasing, the decreasing rate is very slow. 

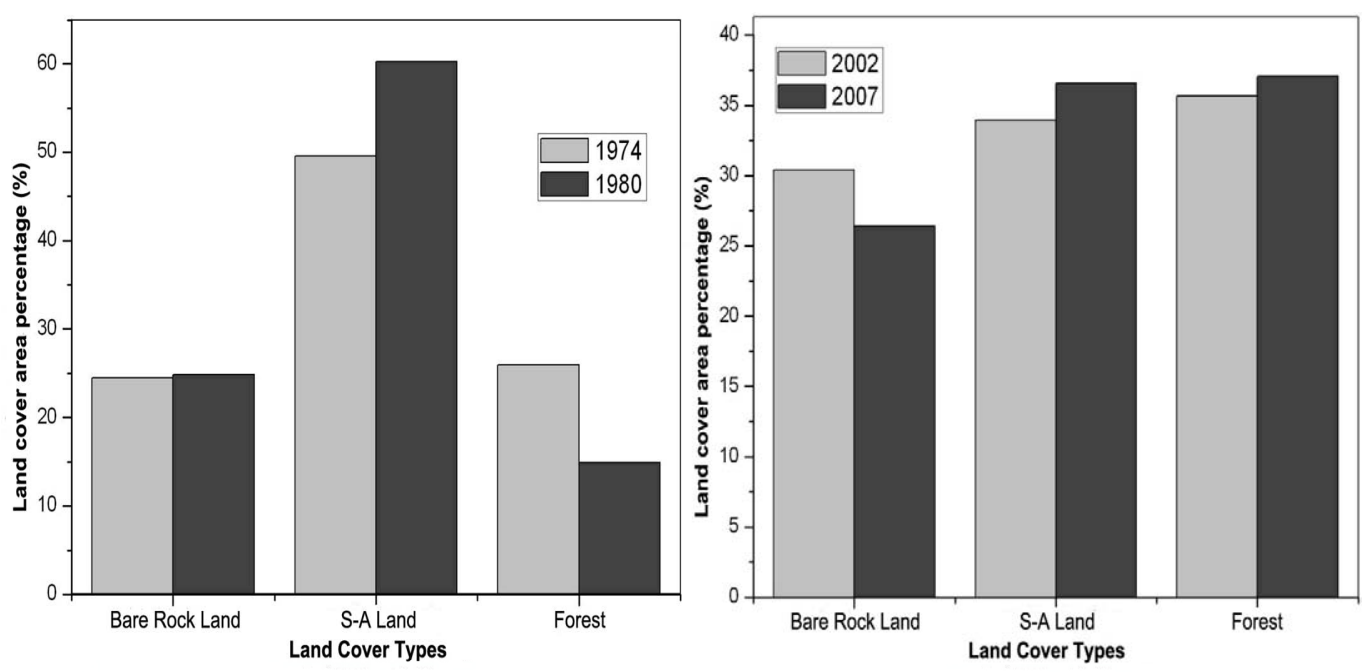

Figure 7. Land cover area change (left: 1974-1980, right: 2002-2008).

Table 1. Areas of Different Land Cover Types in the Period from 1970 to 1980

\begin{tabular}{|c|c|c|c|c|c|}
\hline \multicolumn{2}{|c|}{ Land cover type } & $\begin{array}{l}\text { Bare rock } \\
\text { land }\end{array}$ & S-A land & Forest & Total \\
\hline \multirow[t]{2}{*}{$\begin{array}{l}\text { MSS in } \\
1974\end{array}$} & $\begin{array}{l}\text { Area } \\
\left(\mathrm{km}^{2}\right)\end{array}$ & 5125.94 & 10370.44 & 5434.00 & 20930.38 \\
\hline & $\begin{array}{l}\text { Ratio } \\
(\%)\end{array}$ & 24.49 & 49.55 & 25.96 & 100.00 \\
\hline \multirow[t]{2}{*}{$\begin{array}{l}\text { MSS in } \\
1980\end{array}$} & $\begin{array}{l}\text { Area } \\
\left(\mathrm{km}^{2}\right)\end{array}$ & 5197.94 & 12607.63 & 3124.81 & 20930.38 \\
\hline & $\begin{array}{l}\text { Ratio } \\
(\%)\end{array}$ & 24.83 & 60.24 & 14.93 & 100.00 \\
\hline \multicolumn{2}{|c|}{$\begin{array}{l}\text { Ratio of area } \\
\text { increase }(\%)\end{array}$} & 1.40 & 21.57 & -42.50 & \\
\hline
\end{tabular}

Table 2. Areas of Different Land Cover Types in the Period from 2002 to 2007

\begin{tabular}{|c|c|c|c|c|c|}
\hline \multicolumn{2}{|c|}{ Land cover type } & \multirow{2}{*}{$\begin{array}{l}\text { Bare } \\
\text { rock land } \\
6363.63\end{array}$} & \multirow{2}{*}{$\begin{array}{l}\text { S-A } \\
\text { land } \\
7100.94\end{array}$} & \multirow{2}{*}{$\begin{array}{l}\text { Forest } \\
7465.81\end{array}$} & \multirow{2}{*}{$\begin{array}{l}\text { Total } \\
20930.38\end{array}$} \\
\hline $\begin{array}{l}\text { MODIS } \\
\text { in } 2002\end{array}$ & $\begin{array}{l}\text { Area } \\
\left(\mathrm{km}^{2}\right)\end{array}$ & & & & \\
\hline & $\begin{array}{l}\text { Ratio } \\
(\%)\end{array}$ & 30.40 & 33.93 & 35.67 & 100.00 \\
\hline \multirow[t]{2}{*}{$\begin{array}{l}\text { MODIS } \\
\text { in } 2007\end{array}$} & $\begin{array}{l}\text { Area } \\
\left(\mathrm{km}^{2}\right)\end{array}$ & 5527.56 & 7648.38 & 7754.44 & 20930.38 \\
\hline & $\begin{array}{l}\text { Ratio } \\
(\%)\end{array}$ & 26.41 & 36.54 & 37.05 & 100.00 \\
\hline \multicolumn{2}{|c|}{$\begin{array}{l}\text { Ratio of area } \\
\text { increase (\%) }\end{array}$} & -13.14 & 7.71 & 3.87 & \\
\hline
\end{tabular}

Vegetation decrease in the northeast of the study area in recent years is due to the influence by the frequently human activities around this area. However, vegetation in this area increased in the 1970s. The increases of S-A land area and forest area as well as the decrease of bare rock land area were all due to the "grain to green" policy implemented during the 1970s. In summary, the human activities can significantly influence the ecological environment, and the excessive de- forestation could cause huge destructions to the ecological environment which can be hardly recovered within a short time.

\subsection{Unsupervised Classification Comparison}

Figures 5 and 6 present the unsupervised classification results. The land cover types were divided into three categories, including bare rock land, A-S land and forest. Bare rock land mainly consists of rock in the valley and deforested bare land; A-S land is widely distributed in the high-altitude areas (i.e. altitude over 2,800 m) and middle-altitude areas (i.e. altitude of $1,000 \sim 2,000 \mathrm{~m}$ ), and it is the transition area between bare rock land and forest; Forest is the most important category in the classification maps, and it consists of almost all the types of forest in study area. From Figure 5, it can be found that the major land cover change in the 1970s was related to the forest increase in the northwest and decrease in the middle and the southeast of the study area, as well as the greatly increase of bare rock land in the west. From Figure 6, it is observed that the forest in the middle and the west part of the study area was kept increasing while the bare rock land was decreasing in recent years.By calculating the areas of each land cover category from the unsupervised classification results within different time period, the results of classification change detection are shown in Tables 1 and 2 as well as in Figure 7. From the left part of Figure 7, it can be seen that during the period from 1974 to 1980 , the areas of bare rock land and S-A land increased, particularly the area of S-A land increased rapidly, and in the meantime, large area of forest decreased. On the contrary, the right part of Figure 7 shows the opposite trend. Forest was kept growing with an area of over 30\% of the entire study area. The S-A land area was also kept increasing, while the bare rock land was kept decreasing with a slow rate. In summary, the ecological environment was adversely influenced in the 1970s. However, it was gradually recovered in recent years.

In order to better understand the human impacts on the 
vegetation, it is important to compare the land cover type change rate within two different time periods. Figure 8 shows that the forest in the study area decreased very fast (i.e. $7.08 \%$ per year) while the S-A land also increased rapidly (i.e. 3.60\% per year) in the 1970 s, leading to the deterioration of the ecological environment. This phenomenon was caused by negative activities such as excessive deforestation since the wood from forest was the major economic source in the study area during that time period. After the implementation of "grain to green" policy and natural forest protection project as well as the restriction of human activities within the study area in recent years, bare rock land greatly decreased (i.e. $2.63 \%$ per year) while forest began to increase (i.e. $0.77 \%$ per year) and vegetation in the entire area was gradually recovered. By comparing the unsupervised classification images, it can be found that all the nature reserves within the study area were in relatively stable conditions. Vegetation in these reserves was well kept and almost no bare rock land was found in these areas, and this result illustrates that the nature reserves have buffering capacity and are able to effectively protect the ecological environment. In summary, similar results were obtained by using the two land cover change detection methods (i.e. NDVI differencing and unsupervised classification comparison) in this study.

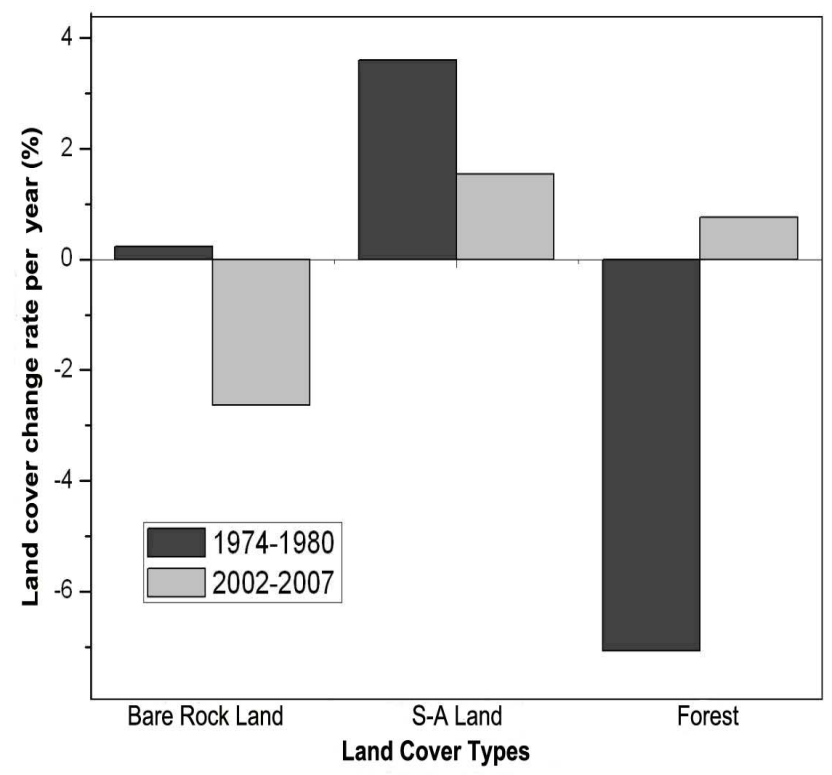

Figure 8. Land-cover area change rate within two time periods.

\section{Conclusions}

The land cover changes in Liangshan-Xiangling region in southwestern China were investigated using two types of remote sensing data, and the change rates among different land cover types were analyzed to explain the ecological environment changes in the study area. Two change-detection methods were used for the analysis, including NDVI differencing and unsupervised classification comparison, and similar results were obtained. It was found that during the 1970s, the bare-rock land and S-A land areas increased rapidly (i.e. increase rate of $3.60 \%$ per year for S-A land) while the forest area decreased significantly (i.e. decrease rate of $7.08 \%$ per year). The deterioration of ecological environment during this time period was caused by negative human activities such as excessive deforestation. After the implementation of positive ecological protection policies and the establishment of several nature reserves within the study area in recent years, the ecological environment has been gradually recovered. The bare-rock land greatly decreased with a rate of $2.63 \%$ per year, and the forest area was increased with a rate of $0.77 \%$ per year, while the forest covered an area of over $30 \%$ of the entire study region. The S-A land area was also kept increasing. The results indicated that human activities would significantly affect the surrounding ecological environments, and the effective ecological protection strategies (such as the establishment of nature reserves) are required since the ecological environments are hard to be quickly recovered after destruction.

\section{References}

DeFries, R.S., Townshend, J.R.G., and Los, S.O. (1997). Scaling landcover heterogeneity for global atmosphere-biosphere models, Scale in remote sensing and GIS, 231-246.

Jensen, J.R. (1981). Urban change detection mapping using Landsat digital data, The American Cartographer, 8, 127-147.

Jensen, J.R., and Toll, D.L. (1982). Detecting residential land-use development at the urban fringe, Photogrammetric Eng. Remote Sensing, 48, 629-643.

Jin Q., Liu X., Zhang S.,and Sun Y. (2005). Detect Habitat Changes in Mabian Giant Panda Nature Reserve, China. In: Tang X., Liu Y., Zhang J., Kainz W., eds, Proceedings of the International Symposium on Spatio-temporal Modeling, Spatial Reasoning, Spatial Reasoning, Spatial Analysis, Data Mining and Data Fusion, Beijing: Chinese Academy of Surveying and Mapping, The Hong Kong Polytechnic University, 2005, 105-108.

Jones, K.B., Neale, A.C., Nash, M.S., van Remotel, R.D., Wickham, J.D., Riitters, K.H., and O'Neill, R.V. (2001). Predicting nutrient and sediment loadings to streams from landscape metrics: A multiple watershed study from the United States mid-Atlantic region, Landscape Ecol., 16, 301-312.

Justice, C.O., Vermote, E., Townshend, J.R.G., Defries, R., Roy, D.P., Hall, D.K., Salomonson, V.V., Privette, J.L., Riggs, G., Strahler, A., Lucht, W., Myneni, R.B., Knyazikhin, Y., Running, S.W., Nemani, R.R., Wan, Zhengming, Huete, A.R., van Leeuwen, W., Wolfe, R.E., Giglio, L., Muller, J., Lewis, P., and Barnsley, M.J. (1998). The Moderate Resolution Imaging Spectroradiometer (MODIS): land remote sensing for global change research, IEEE Trans. Geosci. Remote Sens., 36(4), 1228-1249.

Knight, J.F., Lunetta, R.S., Ediriwickrema, J., and Khorram, S. (2006). Regional Scale Land-Cover Characterization using MODIS-NDVI $250 \mathrm{~m}$ Multi-Temporal Imagery: A Phenology Based Approach, GISci. Remote Sens., 43(1), 1-23.

Liu, J.B., and Yang, G.J. (2006). Animal and plant resources in Mamize Nature Reserve and their conservation, Journal of Sichuan Forestry Science and Technology, 27(2), 25-29.

Liu, X., (2001). Mapping and modeling the habitat of giant pandas in Foping Nature Reserve, China. Doctoral Thesis, ITC, The Netherlands.

Liu, Y.B. (2005). Research on construction and management of nature reserves in Liangshan Region, Journal of Xichang College (Natural Science Edition), 19(1), 65-67. 
LP DAAC (Land Processes Distributed Active Archive Center), NASA (United States). https://lpdaac.usgs.gov/lpdaac/products/mo dis product table/vegetation_indices $/ 16$ day_ 13 global $250 \mathrm{~m} / \mathrm{v} 5 /$ terra (accessed May 1, 2007).

Malingreau, J.P., Tucker, C.J., and Laporte, N. (1989). AVHRR for monitoring global tropical deforestation, Int. J. Remote Sens., 10, 855-867, doi:10.1080/01431168908903926.

Mas, J.F. (1999). Monitoring land-cover changes: a comparison of change detection techniques, Remote Sens., 20(1), 139-152, doi:10. 1080/014311699213659.

MDNNRA (Mabian-Dafengding Nature Reserve Authority). (2000). Administration plan for Mabian-Dafengding National Nature Reserve, Sichuan, China, 1-17.

Munyati, C. (2000). Wetland change detection on the Kafue Flats,
Zambia, by classification of a multitemporal remote sensing image dataset, Int. J. Remote Sens., 21(9), 1787-1806.

Nelson, Stacy A.C., Soranno, P.A.,and Qi, J. (2002). Land-Cover Change in Upper Barataria Basin Estuary, Louisiana, 1972-1992: Increases in Wetland Area, Environ. Manage., 29, 716-727.

Singh, A. (1989). Digital change detection techniques using remotely-sensed data, Int. J. Remote Sens., 10 (6), 989-1003.

Stefanov, W.L., and Netzband, M. (2005). Assessment of ASTER land cover and MODIS NDVI data at multiple scales for ecological characterization of an arid urban center, Remote Sens. Environ., 99, 31-43, doi:10.1016/j.rse.2005.04.024.

Townshend, J.R.G. and Justice, C.O. (1988). Selecting the spatial resolution of satellite sensors required for global monitoring of land transformations, Int. J. Remote Sens., 9, 187- 236. 